\title{
Chinese Students in American High Schools
}

\author{
Chun Hei Cheung ${ }^{1}$ \\ ${ }^{1}$ Northfield Mount Hermon, Gill, Massachusetts, USA \\ Correspondence: Chun Hei Cheung, Northfield Mount Hermon, Gill, Massachusetts, USA.
}

Received: September 25, $2021 \quad$ Accepted: October 30, $2021 \quad$ Online Published: November 12, 2021

doi:10.5539/jel.v11n1p65 URL: https://doi.org/10.5539/jel.v11n1p65

\begin{abstract}
There are numerous scholarly articles that focus on Chinese Students' decisions to go overseas and challenges they face in American High Schools. These research generates a holistic view on the subject., with many of them agreeing each other. Yet, despite many scholarly articles discussing this topic, I find few of these studies originate from students who have lived through the experience of having left China to study abroad in the US themselves. This essay will explore and investigate the experience of Chinese students in US high schools through a combination of personal experience and scholarly articles. Some of the results go in accordance with the scholarly articles, while some deviate away from the findings.
\end{abstract}

Keywords: Chinese Education system, American Education system, Gaokao, High School Education, Immigration

\section{Introduction}

The US has been and continues to be one of the most popular destinations for students from China pursuing their education. Despite the existence of many scholarly articles that explain why this trend evolved and the future economic ramifications of said trend, there are few that take into account the personal deliberations of the students who make the decision to leave their country. The unique aspects of education policy in China, combined with the perceived and real advantages of American institutions, serve to create a distinctive pattern of experiences for Chinese students who end up in the US.

\section{The Decision to Go Overseas}

In Vanessa Fong's book Paradise Redefined: Transnational Chinese Students and the Quest for Flexible Citizenship in the Developed World, many working-class Chinese students yearn for an overseas education (Fong, 2011). The question "is the moon rounder abroad?" posed by students in the book shows their idyllic perception of a utopia outside of China, where educational institutions ensure more promising job prospects and higher social status (Fong, 2011). This desire to go abroad stems first and foremost from dissatisfaction with the institutions that exist in their home country, which leaves them hoping for something better.

\subsection{The "Push" Force from China}

One important factor that drives students away from China is its education system. The National College Entrance Examination, commonly known as gaokao, is a college entrance exam that every Chinese student needs to take. With the exception of a small number of students who do not need to take the exam because of their exceptional academic and extracurricular performance, all colleges in China admit students based on their gaokao score. As a result, this exam becomes one of the most important life events for a Chinese person. 


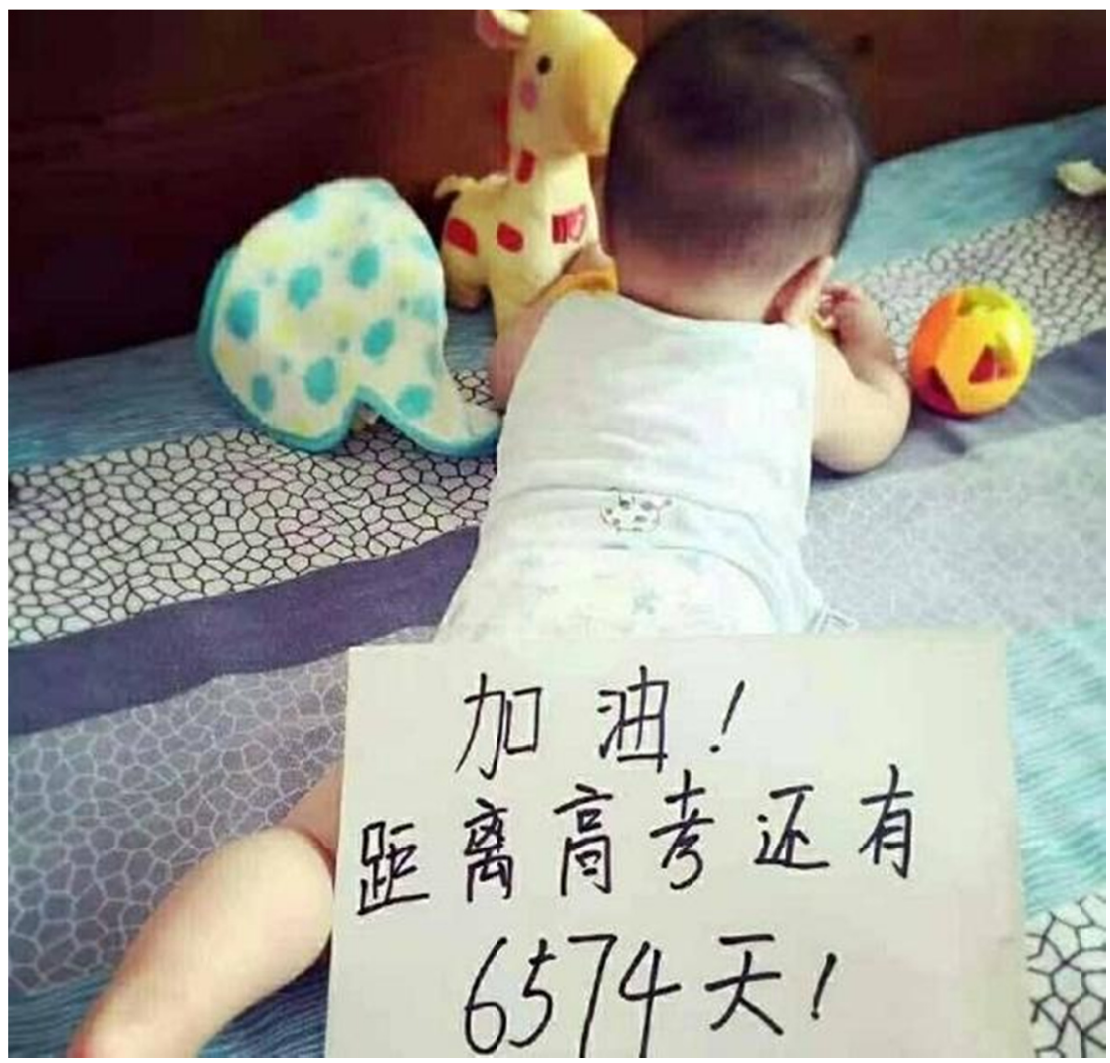

Figure 1. Keep it up! 6574 days until gaokao!

Source: Kknews, 2018.

Above is a picture showing a countdown calendar leading up to the exam, starting from a child's birth (Kknews, 2018). Even if such photos are taken in jest, it is indicative of the immense importance that is ascribed to this test. Just to put the scale of gaokao into perspective, in 2020, 2.2 million students took the SAT (College Board, 2020), while 10 million students took the gaokao (XINHUA, 2020). While nearly 30 of the world's top 50 colleges are in the US, only 2 Chinese colleges, Tsinghua University and Peking University, are ranked among the top 50 colleges globally (The World University Rankings, 2020). It is not hard to imagine how much pressure Chinese students face to earn one of the highly coveted spots in those colleges.

In fact, the selection process for China's top colleges begins not with the gaokao, but with zhongkao, which is the high school entrance exam. With high schools in China being divided into "ordinary" and "key" schools, a student's chances for success are to a significant degree determined by the high school that they attend. "Designated key schools are schools distinguished from ordinary schools by their academic reputation and are generally allocated more resources by the state," which comes with superior teacher quality and a more refined curriculum (China - Secondary Education, n.d.). Because the likelihood of a student to succeed on the gaokao is dependent on their performance on the zhongkao, those who do not perform well on the latter begin to eye possibilities abroad.

The tutoring industry is so ubiquitous in China that it begins to negatively impact China's system of education. This phenomenon is widespread enough that it drives down the teaching quality in schools, because teachers believe that students will cover everything in school during their tutorial classes. In an attempt to boost their reputation, Chinese high schools begin to forgo curriculums aimed towards developing well-rounded, critical thinking minds, tailoring their lesson plans instead towards gaokao preparedness, which alienates parents who are looking for a more well-rounded education for their child.

China's competitive education system has been described as an involution (neijuan). According to an article from BBC (Wang \& Wang, 2021), involution originated as an anthropological term that "refers to a social concept where population growth does not result in productivity or improved innovation." However, in Chinese usage, involution is better translated as one's endless pursuit of improvement due to an unwillingness to fall behind in competition. This concept is increasingly popular in China, with hashtags related to involution receiving over a 
billion views, and the word itself being one of China's top 10 buzzwords last year. So what is its connection with the education system in China? It is best explained through a quote by Professor Biao Xiang from the University of Oxford: "The young continue to feel if they do not work hard or participate in competitions they will be ousted by society, but they do not see a breakthrough for themselves despite their repeated efforts" (Wang \& Wang, 2021). This competition is not just limited to gaokao, but involves academic olympiads, as well as artistic and athletic achievement. Students sacrifice everything else in pursuit of this infinite loop of improvement, which is one of the reasons why many Chinese students do not have vibrant personalities when compared to their American peers. Students born prior to the abolishment of the one-child policy, which includes anyone born before 2015, bear even more expectations from their family. From grandparents to parents, whole chains of relatives invest their capital and effort on one person, exacerbating involution as every family strives to make their child outperform other children.

In recent years there has been a mounting backlash against involution, most notably with the rise of the "tang ping," or "lying flat" movement. "Lying flat," according to Professor Xiao, is youngsters' desire and action to "give up meaningless competitions" (Wang \& Wang, 2021). However, many see no prospect in "lying flat" in China, as it would put them and their family at a significant disadvantage in China's economy. Thus, another solution is to go overseas; with more internationally renowned colleges abroad, many believe they will face less competition (Ma, 2020).

\subsection{The Pulling Force from the US}

It is widely acknowledged among Chinese parents and students that American education, with its non-standardized and individualized classes, cultivates creativity (Ma, 2020). One obvious way to compare the education systems between China and the US is to explore their pursuit for answers. The common narrative is that Chinese teachers will only accept objective answers, while American teachers allow input from multiple perspectives (Ma, 2020). There are indeed schools in the US that specifically design their curriculums and teaching styles in order to foster creativity, such as the Waldorf Program (Alliance, 2020).

However, based on my lived experience in both education systems, I disagree with this simplification. With subjects like math and science, answers can only be objective and not up to the teachers' interpretation. Even American teachers will not allow answers such as " $1+1=3$," which contradict fundamental math principles. On the other end of the spectrum, it makes no sense if teachers only accept one-sided answers within humanities and arts subjects. Students can have multiple interpretations of a piece of art; still, teachers from both China and the US will not force students to only interpret it from one perspective, contrary to what people might believe. In recent years, there have been many scholarly articles about school conformity and creativity in US schools, such as Sugarman (1967), Saldana (2013), and Delgado-Gaitan (1988), so it is well-evidenced that schools, in the US and China alike, demand conformity from students. The fact that schools demand conformity makes a lot of sense because school is indeed a place to cultivate good citizens for society, and certain norms have to be enforced ubiquitously. The conformity cultivated among students kills creativity, however, because students are expected to respect and follow authority instead of doing things on their own. Thus, the view of American schools as steroids for creative thinking is not exactly what the research shows.

Similar to creativity, the emphasis on critical thinking is part of the allure of the American education system for Chinese students. However, it is helpful to question some assumptions made by Chinese parents and students whose perspectives may be shaped by a "grass is greener" syndrome. The advantages of an American education have been embellished by Chinese education agencies that assist students with college applications and test preparations, and have an interest in generating demand for American educational institutions. The propagated narrative is that China's dull education style, defined by rote-memorization, test-oriented education, and dichotomous right-or-wrong thinking, suppresses critical thinking abilities. In order to cultivate this indispensable skill, parents should send their children to the US. For example, many American boarding high schools utilize the Harkness table, which is a round table surrounded by students in order to more easily facilitate discussion and open-ended questions, which is said to nurture students' critical thinking. The encouragement of reading after class is also a major reason why parents believe that their children will eventually acquire critical thinking in an American high school.

However, discussion-based learning is not as effective as we believe in cultivating critical thinking skills. Not every student will speak up during a discussion, thus the intended effect of discussion does not happen among all students. Some students actually hope to get rid of these discussions as they think these are useless, and they can learn more in a shorter period of time with lecture-based learning. Thus, discussion-based learning leads to the development of critical thinking only among those who were already prone to debate and public speaking, leaving 
many, particularly those unfamiliar with this system of learning, on the sidelines.

With the No Child Left Behind Policy of 2001 (NCLB), many American public schools became test-oriented as they struggled to meet the standard minimum test scores. Even though most Chinese public schools have the same standardized system, the belief that American education is entirely open and individualized is flawed. This test-based objective oftentimes leaves no room for discussion-based learning. Some schools do not have the experts who would be able to effectively execute a discussion-based curriculum, and only utilize it for the sake of increasing their positive reputation. Instead of engaging in thoughtful conversations, students participate at the bare-minimum level, leading to dull discussions that do not help build students' critical thinking. Evidence suggests that America's discussion-based approach to cultivating critical thinking does not always bear much better results than China's test-oriented education due to low student participation and a paralleled pressure to succeed on standardized testing. Luckily, NCLB has been replaced in 2015 by the Every Student Succeeds Act (ESSA), which gives states and public school districts more flexibility to design their own curriculums and reduce the effect of test-oriented education on critical thinking. Indeed, ESSA has been living up to its promises and contributing to schools positively (Batel, 2018).

Another big factor for critical thinking is reading. With regards to high school students reading books, numerous scholarly articles (Hosseini et al., 2012; Ibrahim \& Shihab, 2011; Aloqaili, 2012) indicate a strong positive correlation between reading comprehension and critical thinking; through reading, critical thinking can be enhanced. Given that we know the benefits of reading on critical thinking, the question becomes whether reading is happening in American schools, and is it implemented in the curriculum correctly? The answer to the first question is yes - reading is indeed happening in many American schools. However, it is implemented in a way that cannot spark students' interest in reading long term. If you randomly ask an American student whether they like reading or not, the answer is likely to be no (Ingraham, 2018). Moreover, the dislike toward reading scales up as students enter higher grades (Gallagher, 2009), which implies that increased time in school diminishes interest in reading. "High-interest reading is being squeezed out in favor of more test preparation practice. Interesting books are disappearing as funding is diverted to purchase 'magic pill' reading programs" (Gallagher, 2009). As a result, critical thinking is not likely to be cultivated in schools and reading programs if succeeding on benchmark and other standardized testing is the primary aim of the school.

On the other hand, reading books has seen a resurgence among Chinese students as more advertisements encourage students to read. In the past few years, there has been a surge in "reading camps" that guide students to read and cultivate their interest in reading. This new trend is in part due to a desire among educational agencies who seek new opportunities within the marketplace. There are even courses claiming to teach children to "read more than 100,000 words in minutes" (Zuo, 2019), which showcases how far these educational agencies will go in helping students to read, even though the incentive is monetary. America is clearly not the only place where students' interest toward reading can be cultivated.

Despite the many shortcomings of American education, Chinese parents continue to strive to send their children to US schools. Whether it is because they think that attending a US school may be better for their child's mental health, as they will have physical and creative outlets, or because they think that America can better prepare them for the job market, thousands of Chinese students find themselves studying in US private schools. Many of these students, however, find themselves ill-prepared for the challenges they face in American high schools.

\section{Challenges Faced by Chinese Students in American High Schools}

While there are many articles that look into the struggles of Chinese students in the US (Luo, 2013; Liu, Vogel, \& MacLeod, 2016; Yuerong et al., 2017; Fong, 2011; Ma, 2020), those articles are often not in conversation with each other and do not touch on all of the points that will be covered below. This section will give a holistic description of the problems faced by the Chinese student, putting the challenges in context and explaining their relevance.

\subsection{Academic Area}

US education has adopted a Socratic-method oriented learning approach, defined as the involvement of "overt and private questioning, expression of personal hypotheses, and a desire for self-directed tasks" in class (Tweed \& Lehman, 2002). This involves teachers giving students opportunities to express their thoughts and allow other students to question and learn from them. Numerous scholarly articles have pointed to Chinese students' low participation in discussions in American schools (Liu, Vogel, \& MacLeod, 2016; Ma, 2020). This phenomenon is especially evident when the class materials rely on American cultural knowledge that is new to Chinese students. This is in great part due to the fact that expressing personal opinions is considered impolite in Chinese culture, and thus it is a hard habit to develop for them in high school (Yuerong et al., 2017). As a result, Chinese students learn 
not to speak too much, especially in front of those who are older than them, as they grow up. Since class participation accounts for a significant portion of the student's final grade, Chinese students see this as a major academic obstacle.

The pressure that students feel to succeed in a foreign country sometimes forces them to cheat, which is another major challenge. Because cheating becomes prevalent within the community of Chinese students in America, teachers and peers begin to generalize that behavior even to students who do not cheat, leading to stereotyping and frustration (Ma, 2020). Given that the culture of seeking help for mental health has only recently developed, and has not permeated Chinese society, both the cheating students and those falling victim to stereotyping do not utilize the resources to seek help.

\subsection{Social-Cultural Area}

Chinese students also encounter immense obstacles when it comes to social and cultural integration. There is much research on Chinese and American cultural differences (Redmond, 2000; Morris \& Peng, 1994), so it should come without surprise that many Chinese students experience great cultural shock when they first study in America. Chinese students might struggle to understand the importance of respecting others' privacy, or adapting to an individualistic environment from a collectivistic past experience. These cultural differences begin to take a toll on the general happiness of the students, and creates a difficult working environment (Yuerong et al., 2017).

I will resort to a personal experience that illustrates the cultural shock faced by Chinese students. In China, gender is strictly divided into either male or female. Therefore, the idea of LGBTQ is distant to many Chinese students. I did not even know of the use of personal pronouns prior to my arrival in the US. However, the LGBTQ community has been growing rapidly in the US, and gender and sexuality have become extremely relevant topics, especially amongst adolescents. As my school is situated in the New England area and most people here are left leaning, many students can comfortably present their pronouns and sexual preferences. Earlier this year, one of my Chinese friends was moving into school as his visa recently got approved. Coming from a Chinese public school, he had little idea about the great differences between Chinese and American cultures and so frequently made jokes about people being gay. Even though his message was never intentionally malicious, his comments would often land as tone deaf on my classmates' disgruntled ears. One time, he again made a joke about people's sexual preferences; at this time, his comments were heard by another student who is gay. This student criticized his comment angrily, and my Chinese friend was left confused as the other student stormed out of the room. He later asked me what happened with his comment, and he realized his ignorance concerning the LGBTQ community and how he had been creating uncomfortable situations for his peers. This experience gives a vivid picture of how Chinese students struggle to fully understand American culture. They cannot be blamed because in China, making homophobic jokes is the norm, and these students are simply unaware that there is anything wrong when they continue their behavior. Unfortunately, this results in cultural divergence as their American peers distance themselves from Chinese students. This segregation exacerbates the problem of cultural misunderstanding as Chinese students have less opportunity to interact with Americans, leading to the formation of cultural cliques.

Due to vastly differing cultural values, Chinese students often face social exclusion (Bartlett \& Fischer, 2011; Liu, Vogel, \& MacLeod, 2016). The existence of a separate Chinese social media furthers the problem as Chinese students only hang out among themselves (Ma, 2020). According to Liu, Vogel and MacLeod (2016), "international students who succeed in their new environment heavily rely on both social support and social connectedness" (Sam, 2001; Furnham \& Alibhai, 1985). By binding themselves to like-minded peers, Chinese students can find social comfort among themselves. This isolation becomes a problem because it severely limits their social interactions and their learning experience. It becomes even worse when the school does not have a lot of Chinese students, which makes the few who are there feel even more excluded with not many friends of any ethnicity. While there are some who step out of their comfort zone and manage to integrate, it is certainly not the trend.

Before studying in my current American high school, I had only attended public schools in China and Hong Kong. The transition between these two cultures created quite some trouble for me as I struggled to make valuable connections on campus. Most of my Chinese friends were stuck in China due to their inability to acquire their student visas. In other words, I was forced to make friends with new people, people from different countries and cultures. It was difficult initially as I lacked the language skills to express myself. It was worrying as I saw many others had their own friend groups, while I only had a couple of friends. However, I gradually learned from my mistakes as I explored different mindsets and social skills that could help me make friends. I eventually made many friends from different countries, ranging from Bulgaria to Malaysia, from Vietnam to Russia. I could not guarantee having made all these desirable relationships if all my Chinese friends were on campus, but I am more 
than grateful for all the friends I have and their support that helped me navigate through my freshman year.

\subsection{Stress and Anxiety}

Every research paper that I read addressing difficulties faced by Chinese students, agrees that one of the biggest challenges is the language barrier (Yan \& Berliner, 2011; Tweed \& Lehman, 2002; Lin, 2006). Many Chinese students have the will to improve their English by conversing with their American peers, but with the cultural difference this process becomes more difficult. The above-described trend of social isolation among Chinese students directly leads to a decrease in opportunities to improve their oral English skills, and this cycle traps Chinese students from ever improving (Yan \& Berliner, 2011). While preparation for standardized tests such as the TOEFL and SSAT guarantees that the students know how to read and write in English, TOEFL being a test for non-native English speakers and SSAT being a test for private American middle and high school admission, they cannot help students with their actual oral English and social skills. A Chinese student can score really high on TOEFL and struggle to communicate withAmericans due to his accent and anxiety. This problem hinders participation in class discussions, and creates the academic struggles alluded to earlier.

One of the reasons Chinese students decide to study in the US is because of their anxiety towards the gaokao. They believe that there will be less stress if they study in an American high school, as there will be less time dedicated to school and more time allocated for different kinds of activities. However, it is safe to say that testing culture does not change even though they choose to study in the US. With even more forms of standardized tests, such as the TOEFL, SAT, and APs, Chinese students experience chronic stress as they struggle to achieve an excellent score in these tests to succeed in college applications (Ma, 2020). American college applications also do not get easier because students from all over the world flock to the US and compete for some of the best ranked colleges located in the US. While earlier generations of Chinese students might have received scholarships for their overseas studies (Fong, 2011), more students are now self-funded with their own families' capital to go overseas. In other words, they bear even more family expectations to succeed in their overseas education, as failure means the waste of huge sums of family resources. On the other hand, the inability to fit in due to the language barrier and lack of cultural understanding subjects them to peer pressure as they see their classmates making valuable friendships. The lack of social support makes the Chinese students frustrated as they face all of these problems by themselves.

\section{Conclusion}

The decision to travel overseas can be a very difficult one for a family to make. A combination of practical considerations regarding the success of their child, coupled with a desire to see them flourish and develop as individuals, pushes many families to make the financially burdensome leap of faith. As this paper has tried to show, many of the perceived benefits of a foreign education are in fact not as salient as many are made to believe. What also often goes unsaid about the experience of the Chinese in America is how many challenges the students face, both socially and academically. Many of the reasons that the Chinese come to America for, such as the reduction of stress and increased chances of admission, do not actually bear any fruit. The intention behind this paper is to generate understanding of both of the trends that lead to a mass influx of Chinese to America, but also of their experiences abroad. It is important for Chinese students to understand what they will face once they study in the US, and I hope that they can make more well-informed decisions after reading this paper.

\section{References}

Alliance. (2020). Who We Are. Alliance for Public Waldorf Education. Retrieved from https://www.publicwaldorf.org/who-we-are

Aloqaili, A. S. (2012). The Relationship between Reading Comprehension and Critical Thinking: A Theoretical Study. Journal of King Saud University - Languages and Translation, 24(1), 35-41. https://doi.org/10.1016/j.jksult.2011.01.001

Bartlett, T., \& Karin, F. (2011). The China Conundrum. The New York Times, sec. Education. Retrieved November 3, 2011, from https://www.nytimes.com/2011/11/06/education/edlife/the-china-conundrum.html

Batel, S. (2018). ESSA Analysis: How States Are Looking to Drive Stronger School Climate Through New Education Plans. https://www.the74million.org/article/essa-analysis-how-states-are-looking-to-drive-stronger-school-climate -through-new-education-plans/

China - Secondary Education. (n.d.). China - Secondary Education. Retrieved August 26, 2021, from https://education.stateuniversity.com/pages/273/China-SECONDARY-EDUCATION.html

College Board. (2020). Nearly 2.2 Million Students in the Class of 2020 Took The SAT At Least Once-Newsroom. 
Retrieved

from

https://newsroom.collegeboard.org/nearly-22-million-students-class-2020-took-sat-least-once

Delgado-Gaitan, C. (1988). The Value of Conformity: Learning to Stay in School. Anthropology \& Education Quarterly, 19(4), 354-381. https://doi.org/10.1525/aeq.1988.19.4.05x09221

Fong, V. (2011). Paradise Redefined. Stanford University Press. https://doi.org/10.1515/9780804781756

Furnham, A., \& Naznin, A. (1985). The Friendship Networks of Foreign Students: A Replication and Extension of the Functional Model. International Journal of Psychology, 20(3-4), 709-722. https://doi.org/10.1080/00207598508247565

Gallagher. (2009). Readicide. Stenhouse Publishers. Retrieved from https://www.stenhouse.com/content/readicide

Hosseini, E., Fatemeh, B. K., Shahrzad, S., \& Hamid, R. D. (2012). Exploring the Relationship Between Critical Thinking, Reading Comprehension and Reading Strategies of English University Students (p. 9).

Ibrahim, D., \& Abu, S. (2011). Reading as Critical Thinking.

Ingraham, C. (2018). Analysis | Leisure Reading in the U.S. Is at an All-Time Low. Washington Post. Retrieved from

https://www.washingtonpost.com/news/wonk/wp/2018/06/29/leisure-reading-in-the-u-s-is-at-an-all-time-lo $\mathrm{w} /$

Kknews. (2018). The baby is 6574 days away from the college entrance examination. Education should start from the baby. Retrieved from https://kknews.cc/education/qn89rqy.html

Lin, C. C. (2006). Culture Shock and Social Support: An Investigation of a Chinese Student Organization on a US Campus. Journal of Intercultural Communication Research, 35(July), 117-137. https://doi.org/10.1080/17475750600909279

Liu, D. F., Linda, R. V., \& Jason, M. (2016). Mitigating Transitional Challenges of Chinese Students in U.S. Higher Education. Higher Education Studies, 6(3), 100. https://doi.org/10.5539/hes.v6n3p100

Luo. (2013). Study: One in Four Chinese Students Drop out of Ivy League Schools. South China Morning Post. Retrieved from https://www.scmp.com/news/china-insider/article/1342846/study-one-four-chinese-students-drop-out-ivy-le ague-schools

Ma, Y. Y. (2020). Ambitious and Anxious: How Chinese College Students Succeed and Struggle in American Higher Education. Columbia University Press. https://doi.org/10.7312/ma--18458

Morris, M. W., \& Peng, K. P. (1994). Culture and Cause: American and Chinese Attributions for Social and Physical Events. Journal of Personality and Social Psychology, 67(6), 949-971. https://doi.org/10.1037/0022-3514.67.6.949

Redmond, M. V. (2000). Cultural Distance as a Mediating Factor between Stress and Intercultural Communication Competence. International Journal of Intercultural Relations, 24(1), 151-159. https://doi.org/10.1016/S0147-1767(99)00028-0

Saldana, P. J. (2013). Power and Conformity in Today's Schools.

Sam, D. L. (2001). Satisfaction with Life among International Students: An Exploratory Study. Social Indicators Research, 53(3), 315-337. https://doi.org/10.1023/A:1007108614571

Sugarman, B. (1967). Involvement in Youth Culture, Academic Achievement and Conformity in School: An Empirical Study of London Schoolboys. The British Journal of Sociology, 18, 151-317. https://doi.org/10.2307/588602

The World University Rankings. (2020). World University Rankings. Times Higher Education (THE). Retrieved August 25, 2020, from https://www.timeshighereducation.com/world-university-rankings/2021/world-ranking

Tweed, R. G., \& Darrin, R. L. (2002). Learning Considered within a Cultural Context: Confucian and Socratic Approaches. American Psychologist, 57(2), 89-99. https://doi.org/10.1037/0003-066X.57.2.89

Wang, F., \& Yitsing, W. (2021). The Buzzwords Reflecting the Frustration of China's Young Generation. BBC News. Retrieved from https://www.bbc.com/news/world-asia-china-57328508 
XINHUA. (2020). China Focus: Over 10 Million Take China's College Entrance Exam amid Tightened Epidemic $\begin{array}{llll}\text { Prevention. } & \text { Xinhua } & \text { English.News.Cn. } & \text { Retrieved }\end{array}$ http://www.xinhuanet.com/english/2020-07/07/c_139194905.htm

Yan, K., \& David, C. B. (2011). Chinese International Students in the United States: Demographic Trends, Motivations, Acculturation Features and Adjustment Challenges. Asia Pacific Education Review, 12(2), 173-184. https://doi.org/10.1007/s12564-010-9117-x

Yuerong, C. L., Renes, S., McMurrow, S., Simpson, J., \& Strange, A. T. (2017). Challenges Facing Chinese International Students Studying in the United States. Educational Research and Reviews, 12(8), 473-482. https://doi.org/10.5897/ERR2016.3106

Zuo. (2019). Speed-Reading Courses in China Branded "Utter Nonsense". South China Morning Post. Retrieved from

https://www.scmp.com/news/china/society/article/3033247/utter-nonsense-not-everyones-same-page-aboutspeed-reading

\section{Copyrights}

Copyright for this article is retained by the author, with first publication rights granted to the journal.

This is an open-access article distributed under the terms and conditions of the Creative Commons Attribution license (http://creativecommons.org/licenses/by/4.0/). 